\title{
El debate sobre las diputaciónes en un escenario de reforma constitucional del titulo VIII
}

\author{
Tomás de la Quadra Salcedo Fernández del Castillo \\ Catedrático de Derecho Administrativo \\ Universidad Carlos III de Madrid \\ tsalcedo@der-pu.uc3m.es
}

\section{SUMARIO}

1. Introducción.

2. Desarrollo y práctica del modelo de relación de las Diputaciones provinciales con las CC.AA a lo largo de 35 años de vida democrática.

3. El papel atribuido a las Diputaciones en la Ley de racionalización y sostenibilidad de la Administración local.

4. Función de las Diputaciones como entes territoriales determinados por la agrupación de municipios en nuestro sistema democrático.

4.1. Fundamentos propios del segundo nivel (provincial) de democracia local: hacer viable, sostener y extender la democracia local al mayor número posible de núcleos de población.

4.2. Fundamentos propios del segundo nivel de democracia local: La solidaridad y el equilibrio intermunicipales.

4.3. Fundamentos propios del segundo nivel de democracia local: La democracia local en su relación con la Comunidad autónoma y con el Estado.

5. Eventual sustituibilidad de las Diputaciones por otras entidades (supramunicipales, el municipio comarca y la garantía del municipio, o la CC.AA) en el desempeño y realización de sus funciones propias.

5.2. Las comarcas como sustitutas de las Diputaciones.

5.3. Organizaciones especializadas como es el caso de agrupaciones de municipios, mancomunidades, consorcios, veguerías, etc.

5.4. Singularidad del problema en Cataluña y en Canarias.

5.5. Otras eventuales alternativas a las Diputaciones provinciales: los distritos urbanos, ciudades no adscritas (distritos urbanos o ciudades sin distrito) y ciudades Estados.

6. Reformas indispensables en las Diputaciones que hagan frente a los derroches corrupción caciquismo, etc.

7. Consideraciones finales.

\section{INTRODUCCIÓN}

Una de las piezas de la organización territorial del Estado, la Provincia en cuanto Entidad territorial, está siendo cuestionada desde muy diferentes puntos de vista y por muy diferentes razones. Los debates están abiertos desde hace ya tiempo y no sólo en España, sino también en otros países europeos. En Francia e Italia el debate sigue siendo muy vivo. En el reciente referéndum italiano del mes de diciembre de 2016 la supresión de la mención de la provincia en la Constitución era uno de las cuestiones sometidas al pueblo'.

1 Vid. VANDELLI, Luciano “Italia en la vorágine de las reformas: de las ciudades metropolitanas al Senado de las autonomías" en Anuario del Gobierno Local, núm. 1, 2013, sobre el tema de “¿Un nuevo gobierno local en España? La reforma de la Administración local en la Ley 27/2013)", págs. 203-222; ZINZI, Gianpiero “El destino de las entidades provinciales italianas en las manos de una política de gobierno contradictoria” en Revista General de Derecho Administrativo, núm. 37 (2014), págs. 1 y ss.; también BOTO ÁLVAREZ, Alejandra “Los entes locales intermedios: algunas experiencias comparadas dentro de la Unión Europea”, en Memorial para la Reforma del Estado. Estudios en Homenaje al Profesor Santiago Muñoz Machado, CEPC, págs. 2082 y 2085. 
Las provincias o, si se prefiere, la Entidad territorial que personifica los intereses provinciales, es decir las Diputaciones, han sufrido en los últimos años muchos ataques o, cuando menos, objeciones por muy diversas razones. Unas tienen que ver con argumentos que pudiéramos denominar organizacionales; otras con argumentos de carácter democrático y otros con argumentos relativos a los fallos en su gestión y actuación².

Desde el punto de vista organizacional se cuestiona la necesidad de un cuarto nivel de Administración junto al Estado, las Comunidades Autónomas y los Municipios; todos ellos vistos como imprescindibles en tanto que las Diputaciones serían, para algunos, prescindibles y sólo la previsión constitucional se erigiría en una garantía supuestamente injustificada o excesiva de su mantenimiento para quienes las consideran prescindibles.

Detrás de esos reproches organizacionales hay distintas razones no necesariamente incompatibles, sino muchas veces concurrentes: la más plausible radica en un prejuicio contra las Diputaciones por parte de las Comunidades Autónomas que las ven como competidoras políticas. Pero junto a ese prejuicio, bien real, no puede desconocerse que existen otras críticas que invocan fundamentos distintos del simple prejuicio señalado: 1) que el papel de las Diputaciones puede ser desarrollado con ventaja por las comarcas o incluso por Asociaciones de municipios; 2) que una supresión de municipios para evitar municipios inviables haría innecesario el papel de las Diputaciones de apoyo o cooperación con los municipios y especialmente con esos más pequeños ó 3) que sus funciones pueden ser realizadas por las Comunidades Autónomas como se habría demostrado con las Comunidades Uniprovinciales.

Sin perjuicio de analizar a lo largo del presente trabajo las críticas organizacionales descritas puede adelantarse desde aquí que, ciertamente, la Provincia como Entidad territorial ha tenido la enemiga casi generalizada de las Comunidades Autónomas, así como que, en el proceso de la implantación de éstas últimas desde 1979, no han visto con buenos ojos las Diputaciones en cuanto eventuales competidoras de la novísima organización que representaban las Comunidades Autónomas. Pese a la diferencia de posiciones de unas y otras, parecería tal vez como si las Comunidades Autónomas hubiesen necesitado visualizar con todo énfasis su presencia y monopolizar todo el protagonismo de la acción pública pensando que eso legitimaría rápidamente la nueva Institución.

El recelo de las Comunidades Autónomas respecto de las Diputaciones se ha dado en toda España. No sólo en las Comunidades que invocan una supuesta tradición antiprovincial desde finales del XIX -como sería el caso de Cataluña ${ }^{3}$ - sino también en aquellas otras en que no existía esa pretendida tradición. Absolutamente en todas se ha producido tal recelo y desconfianza.

Incluso en aquellas en que la provincia -si bien bajo la forma de territorios históricos- parecía tener unas raíces más profundas, como es el caso del País Vasco, la desconfianza de la nueva Comunidad Autónoma se percibió, como puso de relieve la división del PNV con ocasión de la tramitación de la Ley de Territorios Históricos ${ }^{4}$ en $1983 ;$ pero también, y sobre todo, después, cuando se hicieron patentes los problemas que su aplicación generaba en el desarrollo político de la Comunidad; momento en que se hizo patente dentro del nacionalismo vasco la lucha por el poder, siendo las Diputaciones forales el instrumento de una parte del Partido Nacionalista Vasco para limitar el poder de la otra, la situada en el gobierno de la Comunidad. El peso de las Diputaciones, al margen del invocado profundo amor por ellas de cada territorio histórico, no deriva sólo de la tradición y de la historia, sino, paradójicamente, de la Constitución de 1978 que por haber llevado a la adicional primera de la Constitución los derechos históricos como instrumento para obtener un régimen singular, ha dejado sujeta la Comunidad a ese historicismo provincial al que ha quedado sometida ella misma en materia de organización territorial.

2 Sobre las diversas posiciones puede verse con carácter general y entre muchas otras obras y trabajos COSCULLUELA MONTANER, Luis, “El debate sobre la abolición de la provincia y la reforma de las diputaciones", Anuario del Gobierno Local 2011, de la Fundación Democracia y Gobierno Local 45 Institut de Dret Públic; Escribano Collado, Pedro, "Provincias y diputaciones: una polémica sin proyecto institucional" en Memorial para la Reforma del Estado. Estudios en Homenaje al Profesor Santiago Muñoz Machado, CEPC, pág. 1899 y SS.; SARMIENTO ACOSTA, Manuel Jesús, "Dos cuestiones polémicas sobre la reestructuración del Estado: mapa autonómico y papel de las diputaciones provinciales" en Memorial para la Reforma del Estado..., op. cit., pág. 2031 y ss.; BOIX REIG, V., "Significación de la provincia en la distribución territorial del poder diseñada por la Constitución española”, en Revista de Administración Pública, núm. 115, 1988; JIMÉNEZ ASENSIO, R., “La reforma local: competencias municipales y papel de las diputaciones. Primeras impresiones", Diario del Derecho Municipal, de 4 de julio de 2012 , lustel; ZAFRA VÍCTOR, M., "La provincia: lo importante no es el nombre, lo importante es la función” (I, I???? y IIII), Diario de Derecho Municipal, IUSTEL, octubre 2012 y VV.AA, "Coste y utilidad de las diputaciones provinciales: claves para un debate necesario", Informe de la Fundación ¿Hay Derecho?, 2016, en contra de las Diputaciones por su falta de eficiencia. También ESCUIN PALOP, Catalina, “Algunas reflexiones sobre la Administración local”, en Memorial para la Reforma del Estado. Estudios en Homenaje al Profesor Santiago Muñoz Machado, CEPC, pág. 2014, parece inclinarse por replantearse al menos la cuestión de la conveniencia de mantener la provincia en la Constitución como un Ente local imprescindible.

3 La potente Diputación de Barcelona no podía ser vista con mucha complacencia por parte de la emergente Comunidad Autónoma Catalana, pues mantenía en el mismo escenario de Barcelona en que se desarrollaba la actividad política de la Generalitat un actor cuyo peso y poder económico no podía sino ser visto con mucho recelo.

4 Ley 27/1983, de 25 de noviembre, de Relaciones entre las Instituciones comunes de la Comunidad Autónoma y los órganos forales de sus Territorios Históricos. 
Desde el punto de vista democrático se reprocha a las Diputaciones el ser un ejemplo de democracia no directa de modo que los ciudadanos no eligen directamente a los miembros de tales Entidades territoriales favoreciendo con ello una cierta irresponsabilidad política ante los ciudadanos, puesto que estos no les eligen directamente y por tanto los designados para llevar adelante las funciones de la Diputación no se sienten responsables ante los ciudadanos.

Finalmente, los embates contra las Diputaciones no provienen sólo de razones organizativas o de la enemiga de las Comunidades Autónomas, aunque ésta haya sido relevante o del reproche de su falta democracia. Provienen también de otras circunstancias que no pueden ser desconocidas. Tal es el caso de las críticas a las Diputaciones como un instrumento caciquil de dar y obtener favores sin sujeción a criterios de objetividad o neutralidad; o las críticas por los frecuentes casos de corrupción o nepotismo en el seno de las mismas; o las críticas por los gastos en que incurren en la retribución de sus miembros y de los gabinetes o colaboradores que pueden nombrar 5 .

Tales reproches cobran especial importancia en un momento de crisis económica tan profunda como el que hemos padecido en España desde el 2008; crisis cuyas consecuencias en la ciudadanía hace a ésta especialmente sensible e intolerante, con toda justicia, frente a los excesos que se denuncian.

De todo ello conviene dar cuenta antes de establecer cuál debería ser el mejor método de avanzar y encontrar una solución o al menos una propuesta sobre el futuro de las Diputaciones. Así pues lo primero que se trata de exponer es un breve recordatorio de cómo se ha desarrollado el modelo a lo largo de los años de vida democrática; desarrollo en el que correspondía a las CC.AA asumir un importante rol, para a continuación analizar el significado de la posición en que han ido quedando las Diputaciones en las CC.AA (2), completando dicha aproximación con el análisis de la lógica que preside en la actualidad el papel atribuido a las mismas en la Ley de racionalización y sostenibilidad de la Administración local (3) para concluir abordando la cuestión central de cuál es la lógica que tiene la existencia y función de las Diputaciones como entes territoriales determinados por la agrupación de municipios en nuestro sistema democrático (4) y si ese papel tiene sentido que pueda continuar siendo desempeñado hoy o puede ser desempeñado con ventaja por otras organizaciones (5), así como concluir con las reformas o propuestas de actualización que convendría hacer si es que se tratase de una Institución a conservar para atender las demás críticas de corrupción, caciquismo, falta de democracia o uniformidad (6).

\section{DESARROLLO Y PRÁCTICA DEL MODELO DE RELACIÓN DE LAS DIPUTACIONES PROVINCIALES CON LAS CC.AA A LO LARGO DE 35 AÑOS DE VIDA DEMOCRÁTICA}

Parecía que las Diputaciones iban a jugar un papel mayor que el que habían venido desempeñando a lo largo de su historia a partir del dato de que las novísimas Comunidades autónomas iban a tener necesidad de establecer su propia Administración periférica, salvo en las uniprovinciales. En todas las demás las tareas de gestión y ejecución de las decisiones políticas y de contacto directo con los ciudadanos podrían ser desempeñadas por la organización provincial ya existente: las Diputaciones. Éstas podrían añadir a sus funciones propias como Entidad local, las que les encomendasen o delegasen las Comunidades Autónomas ${ }^{6}$. Los pactos autonómicos, derivados del informe de la Comisión de Expertos que presidió el profesor García de Enterría7, propugnaron esta solución y así se vino a llevar a la LOAPA y permanece todavía hoy en la Ley del Proceso Autonómico vigente. Bien es verdad que frente a lo que a veces se dice, ni en esa Ley ni en el informe de los expertos pretendía imponer esa solución de forma obligatoria, sino que se limitaba al reconocimiento legal de que era posible esa atribución de competencias a las Diputaciones provinciales por parte de las CC.AA ${ }^{8}$.

La historia de estos años ha sido la de cómo ese intento ha sido imposible por la reticencia de las Comunidades autónomas a ceder la más mínima competencia a las Diputaciones o incluso absorber algunas de las que eran propias de éstas últimas ${ }^{9}$. En todo caso debe reconocerse que es muy comprensible tal reticencia a ceder

5 Vid. sobre ello especialmente el informe con muchos datos VV.AA, "Coste y utilidad de las diputaciones provinciales: claves para un debate necesario", op. cit.

6 Vid. ESCUÍN PALOP, V. M., "La delegación de competencias de las Comunidades Autónomas a las Diputaciones Provinciales", en Revista Vasca de Administración Pública, núm. 10, vol. I, 1984.

7 Del profesor GARCÍA DE ENTERRÍA, Eduardo, es el capítulo “La provincia en la Constitución”, en La provincia en el sistema constitucional, GÓMEZ-FERRER MORANT (dir.), Diputació de Barcelona/Civitas, Madrid, 1991, pág. 5 ss.

8 En muchos Estatutos de Autonomía sí se incluyeron previsiones de delegación o articulación que preveían la delegación como una técnica de ordenación de los servicios periféricos; en algunos casos -artículo 4.4 del Estatuto Andalucía, artículo 45.1 del Estatuto de Aragón, artículo 16.3 del Estatuto de Extremadura y 20.2 del Estatuto de Castilla y León-, con fórmulas que parecían constreñir más al uso de la articulación de los servicios periféricos con las Diputaciones Provinciales, aunque dejando en manos de las CC.AA su concreción y en algunos casos previendo la coordinación de las Diputaciones por la Comunidad Autónoma.

9 BOIX REIG, V., "Significación de la provincia en la distribución territorial del poder diseñada por la Constitución española", en Revista de Administración Pública, núm. 115, 1988; también CLAVERO ARÉVALO, Manuel, “La provincia ante una encrucijada histórica”, en Revista de Administración Pública, núm. 100-102 págs. 
el ejercicio de competencias de las CC.AA. La idea podía ser bienintencionada pero no era nada realista, pues es bastante lógico que unas Instituciones nuevas que aspiraban a ser reconocidas por la población, pretendieran ser reconocidas y apreciadas no sólo en la capital donde tuvieran su sede las Instituciones autonómicas, sino por todo el territorio de cada Comunidad. Para ello nada mejor que tener sedes propias desde las que hacer patente la existencia de la nueva Institución a través de la gestión de servicios y el desempeño de tareas y funciones próximas a los ciudadanos; sedes propias para tal propósito no ya en las capitales de cada provincia sino incluso en muchas otras poblaciones de forma que pudiera sentirse la existencia de una nueva Administración que en sus comienzos tenía la sombra del Estado por una parte y de sus Instituciones periféricas (desde los gobernadores civiles, pasando por las delegaciones de Hacienda o -hasta su asunción por las (C.AA- las de educación, sanidad, etc), en las que no habían asumido tales competencias en los primeros años ochenta $\left.{ }^{10}\right)$.

Lo cierto es que aquella recomendación de la LPA y de la Comisión de expertos quedó en nada y probablemente eso tenía su lógica y justificación en razones políticas suficientes o que pesaban más que la pretensión de no duplicar Administraciones. Pero, más allá de ese comportamiento respecto de las Diputaciones, lo que se produjo es una batalla por el control y condicionamiento de las tareas y funciones de éstas últimas. Todo empezó con Cataluña sobre la base de su posición antiprovincialista que probablemente tiene su fundamento en la presencia en la capital de la Comunidad de una Diputación con una potencia tal que sí que podía hacer sombra a la nueva Institución naciente. Por esa o por otras razones que podían invocar las historia o la tradición o el propio proceso pre-autonómico, lo cierto es que la cuestión no consistía tanto en no ceder competencias autonómicas a las Diputaciones sino en imponerles a éstas la cesión de todas las suyas a la Comunidad Autónoma. Cataluña rompe el fuego con su Ley 6/80 de 17 de diciembre de 1980 sobre "Transferencia urgente y plena de las Diputaciones Catalanas a la Generalidad" que hubo de ser declarada inconstitucional en la parte más sustancial de su articulado por la Sentencia 32/1981, de 28 de julio. Pero ese intento de vaciamiento total de las Diputaciones, tuvo continuidad, si bien con otras formas más matizadas, en otras Leyes que igualmente fueron anuladas parcialmente por el Tribunal constitucional. Se trataba de la Ley del Parlamento de Cataluña 5/1987, de 4 de abril, del Régimen Provisional de las Competencias de las Diputaciones Provinciales, $y$, una serie de preceptos de la Ley del Parlamento de Cataluña 23/1987, de 23 de diciembre, por la que se establecen los criterios de financiación de las obras y servicios a incluir en el Plan Único de Obras y Servicios de Cataluña ${ }^{11}$. La Sentencia del Tribunal Constitucional 109/1998 anuló un apartado del artículo $2 .^{\circ}$ de la segunda de dichas Leyes y salvó su artículo 1.1 con una sentencia interpretativa del mismo desestimando las cuestiones de inconstitucionalidad en todo lo demás ${ }^{12}$. Lo cierto es que las competencias de las Diputaciones catalanas quedaron sensiblemente mermadas y muy condicionadas por la CA.

Pero no fue solo Cataluña quien trató de absorber, reducir o condicionar las competencias de las Diputaciones. También Valencia lo intentó con su Ley 2/1983 de 24 de octubre Ley 2/1983, de 4 de octubre, por la que se declaran de interés general para la Comunidad Valenciana determinadas funciones propias de las Diputaciones Provinciales y que condujo a la estimación de la inconstitucionalidad por la Sentencia 27/1987 de 27 de febrero ${ }^{13}$ de varios artículos y a una sentencia interpretativa de algunos otros con un voto particular del Magistrado Rubio Llorente que consideraba que debía haberse extendido el fallo de inconstitucionalidad a algunos más. Lo cierto es que de nuevo las competencias de la Diputación en alguna medida sufrían alguna restricción o condicionamiento.

En otras Comunidades no se llegó al Tribunal Constitucional para dirimir los problemas que planteaban los intentos de coordinar las competencias de las Diputaciones (los planes provinciales eran el caballo de batalla) con las propias de la Comunidad Autónoma. Particularmente relevante es el caso de la Comunidad Autónoma de Andalucía ${ }^{14}$ con su primera legislación al respecto que con la invocación de sus facultades de coordinación previstas en el propio Estatuto (como en otras Comunidades Autónomas) de hecho ahogaba las competencias de las Dipu-

10 Vid. ESCRIBANO COLLADO, P. y RIVERO YSERN, J. L., “La provincia en los Estatutos de Autonomía y en la LOAPA (a propósito del papel de las provincias en la Administración de las Comunidades Autónomas)”, en Revista de Administración Pública, núm. $104,1984$.

11 Vid. sobre el Plan único DE LA QUADRA-SALCEDO FERNÁNDEZ DEL CASTILLO, Tomás, “Corporaciones locales, reforma de los Estatutos y competencias estatales", REDA, 145, págs 48 y ss.

12 El fallo disponía "1. ${ }^{\circ}$ Declarar inconstitucional y, en consecuencia, nulo, el apartado 3 del art. 2 de la Ley del Parlamento de Cataluña 23/1987, de 23 de diciembre, por la que se establecen los criterios de financiación del Plan Único de Obras y Servicios de Cataluña, y las bases para la selección, distribución y financiación de las obras y servicios a incluir en el mismo. 2. Declarar que el art. 1.1 de la mencionada Ley del Parlamento de Cataluña 23/1987, de 23 de diciembre, no es inconstitucional si se interpreta en el sentido expresado en el fundamento jurídico 13 , in fine, de esta Sentencia. $3 .^{\circ}$ Desestimar las cuestiones de inconstitucionalidad en todo lo demás».

13 El fallo disponía "1. Declarar que no son contrarios a la Constitución el art. 2 y los arts. 9 y 10 de la Ley 2/1983, de 4 de octubre, de las Cortes Valencianas, en los términos expresados en los fundamentos jurídicos $5 .^{\circ}$ y $8 .^{\circ}$, respectivamente. $2 .^{\circ}$ Declarar que es inconstitucional y, por lo tanto, nulo, el art. 12 , párrafos $2 .^{\circ}$ y $3 .^{\circ}$, de la mencionada Ley. $3 .^{\circ}$ Desestimar el recurso en todo lo demás".

14 La voluntad centralizadora era evidente. Así MORILLO- VELARDE PÉREZ, José Ignacio, “La provincia en el Derecho propio de Andalucía” Revista Andaluza de Administración Pública, núm. 33, 1999. También REBOLLO PUIG, Manuel y CARBONELL PORRAS, Eloísa, “La Administración local en la Legislación andaluza”, en Tratado de Derecho Municipal (MUÑOZ MACHADO, coord.). Civitas 2003 , págs. 2841 y ss., reconocían la restricción operada sobre las competencias de las Diputaciones. 
taciones, si bien en su nueva Ley 5/2010, de 11 de junio, de Autonomía Local de Andalucía se percibe una posición mucho más flexible ${ }^{15}$ reconociendo la provincia como formando parte de un único nivel de Gobierno y con una visión más abierta de las competencias de la provincia ${ }^{16}$.

Otro modo de limitar las competencias de la provincia ha sido el caso de Aragón a través de una extensión generalizada de comarcas creadas por numerosas leyes que en muchos casos implican una limitación de las competencias de las Diputaciones al realizar algunas de sus funciones ${ }^{17}$. No puede decirse sin embargo que el modelo esté dando los resultados apetecidos en cuanto a gestión, pero sí, tal vez, en cuanto a limitar el papel de las Diputaciones, al segarles por abajo algunas de sus funciones.

En definitiva, no sólo es que, en términos generales, no haya funcionado la descarga de tareas autonómicas en las Diputaciones, sino que las Autonomías, con alguna excepción llena de matices, como puede ser el caso de Castilla y León, han tratado de condicionar y limitar las competencias de las Diputaciones Provinciales en su territorio invocando sus competencias de coordinación previstas en la mayor parte de los Estatutos.

\section{EL PAPEL ATRIBUIDO A LAS DIPUTACIONES EN LA LEY DE RACIONALIZACIÓN Y SOSTENIBILIDAD DE LA ADMINISTRACIÓN LOCAL}

Si hubiera que juzgar el papel y posición de las Diputaciones a la luz de su regulación en la Ley 27/2013 de racionalización y sostenibilidad de la Administración local ${ }^{18}$ podría afirmarse que las mismas han quedado consolidadas frente a la situación anterior y por tanto que el debate ha quedado cerrado con ese fortalecimiento de las Diputaciones. Fortalecimiento hecho, en la intención de la Ley, a costa de los municipios de menos de 20.000 habitantes. Sin embargo, ese fortalecimiento no se ha hecho por las buenas razones, sino sobre la base de las preocupaciones presupuestarias que siendo importantes desde luego no son las primeras que deben inspirar la determinación del papel de las Diputaciones ${ }^{19}$. Por ello, entre otras razones, el debate sobre el papel de la Provincia como Entidad local ha sido cerrado en falso. En primer lugar, y aparte de lo que acaba de decirse, porque son muchas las fuerzas políticas que siguen sosteniendo la conveniencia de suprimir las Diputaciones lo cual garantiza que el debate seguirá estando presente en la vida española ${ }^{20}$. En segundo lugar, y, sobre todo, porque el triunfo de las Diputaciones se ha pretendido construir en la última legislación estatal sobre la sustracción forzosa de competencias a los municipios más pequeños a partir de una concepción municipal tributaria de una visión tecnocrática y puramente presupuestaria y financiera del municipalismo ${ }^{21}$.

Desde tal visión tecnocrática y economicista el lema parecía ser la supresión de los municipios más pequeños (a partir de los de menos de 20.000 habitantes) o su vaciamiento competencial y sobre ese lema pareció quererse fortalecer forzosamente el papel de la Diputación provincial con la vista puesta en esa supresión o vaciamiento de pequeños municipios.

Las sentencias del Tribunal Constitucional 41, 111, 168 y $180 / 116$ han venido a descafeinar parcialmente algo ese programa, pero no puede descartarse que no se pueda repetir el intento con renovados bríos si en un marco de reforma constitucional, se aprovechase la misma para fortalecer de nuevo en el propio texto constitucional la Diputación a costa de los municipios con menos población ${ }^{22}$ o estimulando tanto las fusiones o disuadiendo de

15 Vid. CARBONELL PORRAS, Eloísa, "Las diputaciones provinciales en la Comunidad Autónoma de Andalucía", Cuadernos de Derecho Local (QDL), núm. 31, febrero de 2013, págs. 7-22.

16 Vid. LÓPEZ BENÍTEZ, M., "Desarrollos normativos de las previsiones estatutarias andaluzas sobre régimen local”, en Reforma estatutaria y régimen local (Luis COSCULLUELA y Eloísa CARBONELL PORRAS,Thomson/Reuters-Civitas, 2011 pág. 181.

17 SALANOVA ALCALDE, Ramón, "Las comarcas", Capítulo 26 de Tratado de derecho público aragonés (José BERMEJO VERA y Fernando LÓPEZ RAMÓN, dir.), 2010, págs. 789-808; también CALLIZO SONEIRO, Javier, “Las comarcas, solución aragonesa al minifundismo municipal”, Papeles y memorias de la Real Academia de Ciencias Morales y Políticas, núm. 13, 2005 (La cuestión local), págs. 46-57.

18 Vid. NIETO, A., ORDUÑA REBOLLO, E., SALVADOR CRESPO, M., El bicentenario de las Diputaciones provinciales, Fundación Democracia y Gobierno Local, Madrid, 2012; PAREJO ALFONSO, Luciano "Reflexiones sobre el Gobierno y la Administración locales y su racionalización para garantizar su sostenibilidad”, en Memorial para la Reforma del Estado. Estudios en Homenaje al Profesor Santiago Muñoz Machado, pág. 1899 y ss.; también SALVADOR CRESPO, M., La autonomía provincial en el sistema constitucional español. Itermunicipalidad y Estado autonómico, Fundación Democracia y Gobierno Local, Madrid, 2007.

19 Vid. MORCILLO MORENO, Juana, "El pretendido impulso a la administración provincial en la reforma española de 2013", en Istituzioni del Federalismo. Rivista di studi giuridici e politici, pág. 364 y ss.

20 Es el caso de Ciudadanos y Podemos. También el PSOE aunque parece haber sustituido su posición por la sustitución por un Consejo de Alcaldes.

21 Pese a ello las Sentencias del Tribunal Constitucional dictadas en la materia han limitado, afortunadamente, mucho el alcance pretendido con la Ley 27/2013.

22 Pueden verse las atinadas reflexiones de REBOLLO PUIG, Manuel, “La crisis económica y la oportunidad de reducir el número de municipios" en Crisis económica y reforma del régimen local, coords. Luis COSCULLUELA MONTANER y OTROS, en donde somete a crítica la idea del exceso de municipios y los compara con los existentes en Alemania en pág 196 y ss. 
no hacerlas que vayan más allá de lo que es lícito para transformarse en una coacción como alerta la Sentencia

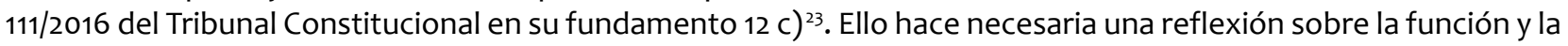
lógica que pueden tener las Diputaciones provinciales desconectada de la coyuntura concreta.

Por otra parte esa misma visión tecnocrática y economicista está presente también en los recortes de libertades municipales que se han insertado con "fórceps" en la Ley 7/1985 de Bases de Régimen local por la Ley 27/2013, de 27 de diciembre, de racionalización y sostenibilidad de la Administración local, alterando el sentido profundo de la autonomía local que inspiraba aquella con la reformulación y práctica supresión del reconocimiento que en su artículo 25.1 se hacía de la competencia (casi capacidad) para "promover toda clase de actividades y prestar cuantos servicios públicos contribuyan a satisfacer las necesidades y aspiraciones de la comunidad vecinal”. Al añadir en la Ley 27/2013 que eso se haga "en los términos previstos en este artículo" se está vaciando de contenido ese reconocimiento de competencia dejándolo sin sentido, por redundante, respecto de lo que se decía originalmente, sin que las previsiones del actual artículo 7.4 de la LRBRL sobre asunción de competencias impropias permita afirmar que se mantiene la capacidad o competencia genérica que el antiguo 25.1 de la versión modificada les reconocía a los municipios. En efecto, actualmente el artículo 7.4 supedita la decisión municipal de ejercer competencias ${ }^{24}$ distintas de las propias a la conformidad de la Administración competente y a la no duplicidad del propio servicio público que no ha de ser prestado por más de una Administración; lo que priva de toda autonomía al ente local que quiera ejercer una competencia no propia al hacer depender su decisión de otra Administración.

Esa misma visión es la que ha llevado a la supresión de las competencias para realizar otras actividades complementarias de las de otras Administraciones, probablemente sobre la base de la condena de las duplicidades competenciales; condena que no tiene asidero alguno en la Constitución. De nuevo tampoco el actual artículo 7.4 de la LRBRL permite teóricamente recuperar esa competencia reconocida en el antiguo artículo 28 de dicha Ley para realizar actividades complementarias, pero al sujetarla a las mismas restricciones, difícilmente aceptables en términos constitucionales por violación de la autonomía local, deja ese reconocimiento en un "flatus vocis".

Es también la que ha llevado a incorporar al fundamental artículo 2 de la LRBRL ${ }^{25}$ la coletilla del respeto a la normativa de estabilidad presupuestaria y sostenibilidad financiera (no sólo pues a la Ley Orgánica prevista en el artículo 135 (E) que deja entregada la esencia más pura de la autonomía local a cualquier norma reglamentaria, orden o instrucción en materia de estabilidad y sostenibilidad.

\section{FUNCIÓN DE LAS DIPUTACIONES COMO ENTES TERRITORIALES DETERMINADOS POR LA AGRUPACIÓN DE MUNICIPIOS EN NUESTRO SISTEMA DEMOCRÁTICO}

En todo caso la función y el papel de las Diputaciones no puede construirse a costa de los municipios de menos de 20.000 habitantes (es decir suprimiéndolos o dejándolos casi forzosamente sin competencias como pretendía la Ley 27/2013 hasta la declaración de inconstitucionalidad de algunos preceptos importantes de esa reforma) o con medidas de estímulo a la renuncia al ejercicio de competencias en beneficio de la Diputación al amparo del artículo 36.2 a) que hagan insoportable el ejercicio de las propias competencias ${ }^{26}$ en cuanto hagan

23 «No puede excluirse en abstracto que los planes provinciales que sean aprobados al amparo de la norma legal de referencia, eventualmente, puedan diseñar mecanismos disuasorios de tal intensidad que solo formalmente preserven los márgenes de autonomía municipal que asegura el art. 26.2 LBRL. Pero, en tal caso, el problema que tal circunstancia pudiera plantear para la autonomía municipal constitucionalmente garantizada (arts. 137 y 140 CE) afectaría estrictamente, no al impugnado art. 26.2 LBRL, sino a los planes que hubieran desvirtuado materialmente la exigencia de "conformidad" que este impone. Por consiguiente, desde la perspectiva de la autonomía local, el precepto analizado no es inconstitucional».

24 Hay una cierta confusión en el 7.4 de la LRBRL actual sobre lo que llama el ejercicio de competencias no propias y lo que sería el desarrollo de actividades económicas o no al amparo del artículo 128 de la Constitución respecto a la iniciativa pública en la actividad económica, que a mayor abundamiento corresponde a cualquier ente de cualquier nivel, sin perjuicio del respeto al principio constitucional de estabilidad presupuestaria.

25 En dicho artículo se contiene la quintaesencia de la autonomía local y las obligaciones que impone a los poderes legislativos del Estado y de las CC.AA. En ninguno de los borradores iniciales del anteproyecto de LRBRL figuraba tal artículo. Cuando ya estaba preparado el último se hizo necesario, antes de elevarlo al Consejo de Ministros para su aprobación como proyecto de Ley, encontrar la fórmula sintética que llevará al texto preparado la garantía de la autonomía local vinculante también y especialmente para los legisladores que no eran libres de hacer lo que quisieran con la autonomía local en trance de regular los distintos sectores de la acción pública. Vinculante no tanto en función de la propia Ley, sino en cuanto expresión del alcance de la autonomía garantizada constitucionalmente.

26 Sobre lo que ya ha alertado la Sentencia 111/2016 por la eventual inconstitucionalidad en que podrían incurrir tal tipo de medidas en el párrafo anterior al antepenúltimo párrafo antes del Fallo (FJ 12, d).

«No puede excluirse en abstracto que los planes provinciales que sean aprobados al amparo de la norma legal de referencia, eventualmente, puedan diseñar mecanismos disuasorios de tal intensidad que solo formalmente preserven los márgenes de autonomía municipal que asegura el art. 26.2 LBRL. Pero, en tal caso, el problema que tal circunstancia pudiera plantear para la autonomía municipal constitucionalmente garantizada (arts. 137 y 140 CE) afectaría estrictamente, no al impugnado art. 26.2 LBRL, sino a los planes que hubieran desvirtuado materialmente la exigencia de "conformidad" que este impone. Por consiguiente, desde la perspectiva de la autonomía local, el precepto analizado no es inconstitucional». 
imposible resistirse a tal renuncia. Ha de construirse más bien con base en las razones constitucionales en que debe inspirarse un modelo de segundo nivel de democracia local que no necesita esquilmar o suplantar obligatoriamente las funciones básicas de la democracia municipal para justificarse. En efecto, su justificación, la de las Diputaciones, está en la prácticamente olvidada, pero básica, función de garantía de los principios de solidaridad y equilibrio intermunicipales que proclama el artículo 31.2 de la LRBRL, así como en el reforzamiento del papel del mundo local en sus relaciones con el Estado y las Comunidades autónomas.

Es necesario explicitar, por tanto, las razones profundas del segundo nivel de democracia local ${ }^{27}$, lo que no significa ni olvidar las reformas que haya que acometer para corregir los defectos que se le imputan (caciquismo, corrupción, gasto excesivo, etc. ), ni tampoco despreciar las justas preocupaciones que laten en el principio de estabilidad presupuestaria llevado por muy buenas razones al artículo 135 de la Constitución, pero desarrollado más allá de sus límites en la Ley Orgánica 2/2012 de 27 de abril de Estabilidad presupuestaria y de sostenibilidad financiera. Ley que, con su propio título, ya demuestra que ha ido más allá de aquello para lo que estaba habilitada por la Constitución: la estabilidad presupuestaria ${ }^{28}$. La sostenibilidad financiera puede ser una exigencia de la UE sobrevenida o incluso convergente con la estabilidad presupuestaria, pero en el plano constitucional interno no cuenta con la habilitación para que la Ley orgánica del artículo 135 de la CE desarrolle la sostenibilidad financiera como algo diferente de la estabilidad presupuestaria. La Ley 27/2013 es tributaria de una visión preocupada por el gasto público y su reducción. Nada hay que decir contra esa preocupación que ya recoge la reforma constitucional del artículo 135, pero sí contra el olvido del significado de otros bienes y valores como el de la extensión de la democracia local, la solidaridad entre poblaciones o el equilibrio intermunicipal. Bienes y valores que nos alertan sobre cómo el segundo nivel nunca se construyó con la idea del gasto, sino con las ideas de la libertad, solidaridad y equilibrio. El hecho de que hoy haya que atender, con toda justicia, al gasto público no significa que haya que olvidar la esencia de las cosas, ni la jerarquía de los valores implicados. La política agrícola común es una muestra de cómo hay cosas que pueden no ser sostenibles o costosas económicamente y sin embargo se apoyan porque están presentes otros bienes y valores que lo justifican. Es preciso valorar pues si hay otros valores que explican el mantenimiento y sostenimiento de Entes locales en función de esos otros valores sin limitarse a tomar como parámetro casi único los aspectos económicos; aunque como es lógico sin dejar de tomarlos en consideración.

\subsection{Fundamentos propios del segundo nivel (provincial) de democracia local: hacer viable, sostener y extender la democracia local al mayor número posible de núcleos de población}

En este caso la esencia de la función de la Diputación consiste en hacer posible y extender la democracia local de primer nivel -la de los municipios- al mayor número posible de núcleos de población. Y ello porque dicho primer nivel, los Ayuntamientos, cumplen una función básica en nuestro sistema constitucional y, probablemente, en cualquier sistema. La esencia de los municipios se puede descubrir en Cádiz cuando en su artículo 310 dispone que se pondrán Ayuntamientos en los pueblos que no lo tengan y en que convenga que los haya; añadiendo que no podrá dejar de haber Ayuntamiento "en los que por sí o con su comarca lleguen a 1.000 almas". Esa cifra marca el mínimo obligatorio para que haya Ayuntamientos, pero no excluye que pueda haberlos, aunque no lleguen a dicha cifra. Es decir, aunque estén por debajo de mil habitantes.

La decisión gaditana se muestra evidente y transparente en aquella coyuntura histórica en que una Nación toma conciencia de sí por las circunstancias históricas de la invasión, resistida por toda España, sin olvidar el comportamiento heroico de tantos municipios a lo largo y ancho de nuestra geografía, ni el primer grito, cuando menos simbólico, lanzado desde un pequeño municipio precisamente. Sin olvidarse tampoco de las Juntas de defensa que se extienden por lo que queda de los restos del Estados concentrados en gran medida en la democracia local.

Pero sobre todo el ejemplo gaditano tiene el valor de la transparencia en cuanto claramente se vincula esa obligación de establecer Ayuntamientos con la idea de democracia constitucional, cuya voluntad es la de acabar con las situaciones de dependencia señorial o patrimonial de quienes no vivían en ciudades o villas. Establecer Ayuntamientos en los pueblos que no los tuvieran, la mayoría entonces, era otorgar un status efectivo de ciudadanía, con instituciones representativas y electivas, que hacían real y operativa la condición de ciudadanos reconocida formalmente en la norma constitucional a todos los españoles en el artículo 18 de la Constitución gaditana. Sobre todo, significaba sacar a la inmensa mayoría de los habitantes, formalmente ya ciudadanos de acuerdo con las

27 Vid. por su interés GARRORENA MORALES, Ángel, "Entidades locales, cuerpos intermedios y libertad en el pensamiento de Alexis de Tocqueville", Anuario del Gobierno Local, 2012, págs. 173-198, que enfatiza la importancia de la Entidades locales en la preservación de la democracia y la libertad.

28 Sobre el tema en general y en su aplicación a los Entes locales puede verse VILLAR ROJA, Francisco José, “El control de la estabilidad presupuestaria local: de nuevo la tutela estatal y sus vicios”, en Memorial para la Reforma del Estado, págs. 2859 y ss. 
palabras de la Constitución, del limbo en que estaban, dado que, por no residir en ciudades y villas, permanecían en la pura, primitiva y feudal dependencia señorial o patrimonial de los propietarios de las tierras que cultivaban, no siendo, así, ciudadanos de ningún sitio.

Eso, y la realidad de una gran dispersión geográfica vinculada con la economía básicamente agraria, explica el gran número de Ayuntamientos que siempre ha habido en España y que tienen que ver con el gran número de núcleos de población que Cádiz vino a elevar a la condición de ciudadanos; y, por tanto, dueños políticos del espacio en que vivían. Número elevado desde entonces, aunque en reducción progresiva, que es motivo de frecuentes lamentos que parecen olvidar, para empezar, que su número no es el fruto de un capricho de nadie, sino de una realidad económica, social y geográfica que determina que haya el número de núcleos de población que la historia, la geografía y la economía, unida a la libre espontaneidad de sus habitantes, han determinado.

A partir de ahí esa realidad humana reclama inevitablemente su capacidad para ordenar la vida en común, el uso de las calles, las fuentes, el acceso a los ríos, puentes, fiestas, etc. En definitiva, cada comunidad humana -unida por su presencia y supervivencia en un espacio común y separado de otras comunidades- reclama como natural su capacidad para ordenar su vida en común y sus necesidades. Se dice a veces que los Ayuntamientos son una escuela de democracia cuando, en realidad, son la democracia misma que se empieza a ejercer en la ordenación y arreglo de las necesidades e intereses propios de carácter local. Probablemente no sea necesario que cada núcleo de población separado se constituya en Ayuntamiento, pero no deja de ser perfectamente explicable y razonable que eso sea así. Eso justifica y legitima desde el punto de vista democrático los Ayuntamientos, incluso en núcleos de población muy pequeños. Y las exigencias de la democracia son aquí el primer valor a considerar, sin despreciar no obstante la posibilidad de estimular la fusión de municipios. También sin despreciar la importancia de mantener estructuras de decisión democráticas que pueden adaptarse en sus competencias y organización a las peculiaridades de los núcleos más pequeños.

Desde luego, habrá que considerar también otros factores, como los económicos y de gasto. Pero no se puede colocar éstos por delante y, menos, como únicos. Tanto menos cuanto que no son los pequeños Ayuntamientos los que tienen que ver con el déficit o la deuda pública, sino los muy grandes como es el caso de Madrid o Barcelona.

Parecería a veces no existir suficiente sensibilidad democrática -la que, en cambio se percibe en la Constitución de Cádiz- cuando adoptando el papel de cirujanos de hierro se proponen operaciones de supresión radical de Ayuntamientos y se recuerdan con emoción algunas operaciones de disminución acometidas en otros países, como Alemania, olvidando las razones reales de la existencia de municipios (si hay los que hay, es porque hay esas comunidades humanas territorialmente diferenciadas) así como la propia extensión superficial de España, más extensa que la de la propia Alemania que a veces se pone como ejemplo ${ }^{29}$, aunque su población sea menor.

Hay como un cierto olvido de la configuración real de los asentamientos de la población y de la lógica democrática que lleva a reconocerles el instrumento formal de constituirse en Ayuntamiento; es decir de tener el instrumento para regirse por sí mismos.

Sea como fuerenadie trata de suprimir, como es lógico, la población misma que vive en esos núcleos, ni desplazarla o concentrarla en otros lugares, ni de privarles de Instituciones de representación, sino de incorporarlas a Instituciones más lejanas en las que estará representado cada núcleo junto con otros de igual tamaño o con un núcleo poblacional mucho más grande que habrá de ocuparse de los problemas del integrado. Pero eso tiene un coste para la comunidad vecinal que se sentía dueña de la gestión de sus intereses; un coste en cuanto sentimiento de lejanía, extrañamiento y pérdida del control inmediata de su destino que queda en manos de otros, que, por buenos que sean, no son la propia comunidad y quedan difuminados en una comunidad más amplia y, a veces, desconocida.

Ese coste que no sólo es sentimental y de pérdida de control de sus destinos, sino un coste en democracia directa que ya nunca volverá a ser la misma. La desaparición como Ayuntamientos para su incorporación o fusión con otros es lo que puede evitar y tiene que evitar la Diputación como segundo nivel, a la vez que permite cohonestar el mantenimiento de ese valor y bien democrático que representa el Ayuntamiento con la viabilidad económica de la prestación de determinados servicios. En efecto, se trata desde siempre de que las Diputaciones asuman el eventual mayor coste (de haberlo pues no siempre ocurre así) que no podrían asumir (extinción de incendios, recogidas de basuras o residuos, tratamiento de aguas, etc.) los municipios más pequeños, cuya subsistencia, sin embargo, es un bien a considerar en términos de democracia.

29 Vid. REBOLLO PUIG, Manuel, “La crisis económica y la oportunidad de reducir...”, op. cit., en donde se enfrenta críticamente a la pregunta de si son un problema los pequeños municipios en págs 212 y ss. 
Las Diputaciones son así un instrumento para hacer posible que la democracia llegue a las más pequeñas comunidades humanas, incluso cuando ellas mismas no sean capaces de asumir determinados servicios. Servicios que, por cierto, en todo caso deberían serles suministrados, aunque no se constituyesen en municipio. La diferencia es que, constituidos en municipios dejaran de sentirse más bien como abonados o beneficiarios de unos servicios, para asumir más plena y realmente su papel de ciudadanos que como colectividad humana conjunta puede tomar las decisiones que a ellos más directamente les afectan. Naturalmente que esos núcleos de población, aunque no se constituyesen en municipios, no dejarán de pertenecer a otro municipio más grande, pero su voz quedará sofocada y difuminada en el manejo en ese municipio mayor en relación con las cosas que a ellos más les interesan.

Quiere decirse con todo ello que la Diputación -luego veremos si ese papel puede ser desarrollado por otra organización- es un instrumento para extender y hacer viva la democracia municipal al mantenerla vinculada a cada grupo poblacional.

Desde esa perspectiva, sin renunciar, en absoluto, al debate del coste, lo que no puede es ponerse éste por delante de todo olvidando la primera función y valor al que sirven las Diputaciones: la democracia. Aunque sin despreciar, ni mucho menos, la segunda función y valor: la viabilidad económica de esa democracia local a través de la garantía de los servicios o de su prestación por un segundo nivel que garantice su viabilidad a través de las economías de escala y alcance que derivan de la gestión conjunta.

Las Diputaciones - $\mathrm{u}$ otras Entidades en su caso- se crean para que pueden existir Ayuntamientos, como instituciones democráticas y representativas, en comunidades humanas donde es bueno y conveniente que las haya, incluso aunque supongan unos ciertos gastos que pueden ser perfectamente asequibles en muchos casos. Pero es superior el beneficio que se obtiene de extender la democracia al mayor número de núcleos de población y comunidades humanas que el pequeño coste que puede implicar establecer estructuras democráticas en esas comunidades locales

\subsection{Fundamentos propios del segundo nivel de democracia local: La solidaridad y el equilibrio intermunicipales}

Pero no se trata sólo de extender la democracia local a núcleos poblaciones más pequeños. Se trata también de que exista entre todos los municipios de una misma provincia -tomada como una extensión territorial de referencia por razones históricas, geográficas o culturales o incluso de simple convención- una función de solidaridad y de equilibrio intermunicipal que proclama el, a veces olvidado, artículo 31.2 de la LRBRL en su comienzo al enunciar precisamente los fines de la Provincia: "garantizar los principios de solidaridad y equilibrio intermunicipales en el marco de la política económica y social". Se pasa por encima esa declaración de la esencia y del papel "funcional" de la Diputación, para pasar a la lista subsiguiente que sigue a continuación en dicho artículo.

Solidaridad y equilibrio son conceptos que aquí están muy conectados, pero que presentan algunas diferencias. La solidaridad implica una voluntad de establecer un sistema que haga que quienes tienen más capacidad y más medios contribuyan al sostenimiento y apoyo de los servicios más esenciales de quienes tienen menos. Que contribuyan de forma que hagan posible la existencia misma de esos municipios que tienen menos capacidad económica y también que hagan posible la dotación de determinados servicios indispensables.

La solidaridad no exige, sin embargo y desde luego, una igualdad absoluta en los servicios y coberturas que se reciben. Nunca será el mismo, ni tiene porqué serlo, el nivel dotacional de una gran ciudad en cuanto a parques y jardines, polideportivos, etc. que el de una pequeña aldea y lo mismo ocurre respecto al servicio de basuras o guardia urbana.

La solidaridad se satisface con una equiparación que se lleva sólo a los aspectos más esenciales de los servicios y que tiene en cuenta que la esencia puede ser distinta en un pequeño pueblo de mil habitantes respecto de uno de cincuenta mil o medio millón de habitantes.

El equilibrio va algo más allá porque trata de que, conseguidos unos mínimos en servicios esenciales y básicos y en la misma existencia de Ayuntamientos, se dé una cierta equiparación, un cierto equilibrio, en otros servicios no tan básicos. Equilibrio que ya no atiende sólo al mínimo básico de servicios esenciales, sino a la supresión de las diferencias excesivas (no sólo respecto de lo mínimo de servicios y prestaciones esenciales, sino respecto de la media en todos los servicios de la población asentada en la provincia). El equilibrio no pretende la equiparación, sino una cierta aproximación. Tampoco pretende que todos los servicios se presten de forma más o menos equiparada en cada municipio, sino más bien facilitar el acceso a los servicios que se presten en los municipios mejor dotados. Las clases de natación a los niños pueden no darse en todos los municipios porque no todos tienen piscinas con 
características adecuadas, ni es conveniente que las tengan; pero el acceso a la piscina de los municipios que la tengan por parte de otros ciudadanos de otros municipios en condiciones de una cierta igualdad, puede formar parte del papel de equilibrio que realice la Diputación condicionando sus ayudas a unos municipios a aceptar el acceso de los vecinos de otros en determinadas condiciones.

Habrá por tanto servicios y actividades que no se pueden extender a todos los municipios. Centros educativos -Institutos-, teatros, polideportivos, Bibliotecas, etc. es posible que no puedan existir en todos los municipios porque la población de los mismos no permita que existan. Pero los que hay en otros municipios vecinos o próximos pueden abrirse al servicio de toda la Comunidad provincial ${ }^{30}$. Se trata de que haya un cierto equilibrio y la referencia de ese equilibrio es el ámbito de la provincia. Y desde la provincia se pueden tener instrumentos para logar tal equilibrio. En la historia de las Diputaciones eso ocurría con hospitales, inclusas, centros de beneficencia, psiquiátricos, museos, teatros, etc., situados generalmente en la capital de la provincia, pero abiertos a todos.

Esta dimensión de la solidaridad y del equilibrio es de suma importancia en la caracterización de la provincia. En realidad, es básica. En efecto, no se trata sólo de hacer posible la primeramente tratada de extensión de la democracia local a comunidades asentadas de forma diferenciada en distintos territorios dentro de la provincia, sino de garantizar que las diferencias de riqueza y medios o las dificultades derivadas de las propias circunstancias geográficas de cada asentamiento no creen diferencias inaceptables entre poblaciones y sobre todo les priven del acceso a algunos de dichos servicios. Esa solidaridad no puede ser tratada de forma separada por cada municipalidad, sino que se atribuyen a la Diputación que queda obligada a asumir desde el principio esa visión provincial solidaria entre los habitantes de la provincia, que se erige así en un primer espacio de la solidaridad y del equilibrio inter-municipal.

Ciertamente la provincia es una Entidad determinada por la agrupación de municipios. Esa determinación tiene reflejo en la composición de la Diputación y en la presencia de los municipios en la Diputación y en el peso de los mismos que no se produce en función de la población de cada municipio ni de la del conjunto de la población de la provincia. Ahora bien, en alguna medida es la población de la provincia, como un todo, la que sostiene la idea de la solidaridad, por más que su concreta interpretación o aplicación en cada caso haya de ser hecha por los representantes que, sin reflejar una directa proporción de la población de cada municipio, toman las decisiones sobre el modo de hacer efectiva esa solidaridad.

Por otra parte, no siempre la solidaridad y el equilibrio se expresa mediante servicios directos que se prestan en todos y cada uno de los municipios, sino que tal equilibrio puede expresarse a través de la distribución a lo largo y ancho del territorio provincial, pero no en todos los municipios, de servicios que se concentran en determinados municipios al servicio de todos los demás próximos. O de servicios o actividades que pueden situarse en la capital de la provincia, pero al servicio de todos los municipios de la provincia. Piénsese en Servicios de extinción de incendios o en recogida de desechos industrial o en tratamiento de residuos, etc.

La Provincia ofrece un espacio suficientemente amplio como para que pueda desarrollarse mejor esa función de solidaridad y equilibrio intra-provincial que en ámbitos más reducidos, como los comarcales. Ello no quita que eso no compense los desequilibrios que puedan producirse entre unas provincias y otras de una misma Comunidad Autónoma. A esta última le corresponderá tomar las medidas para que se produzca ese reequilibrio en el ámbito de la Comunidad Autónoma.

\subsection{Fundamentos propios del segundo nivel de democracia local: La democracia local en su relación con la Comunidad autónoma y con el Estado}

El último rasgo de las Diputaciones tiene que ver con la conexión de la democracia local con el democracia autonómica o estatal ${ }^{31}$. La vida local, la que interesa a los ciudadanos en cuanto viven en un espacio concreto y limitado, se perfecciona haciendo llegar sus aspiraciones y necesidades (naturalmente sólo las vinculadas a ese espacio local y la comunidad local que en él habita) a los niveles superiores de gobierno.

Tal cosa solo es viable para los grandes municipios con poblaciones que se cuentan por cientos de miles o millones de personas. En esas condiciones el resto de los habitantes que no viven en esos grandes municipios carecen de toda posibilidad de acceder a los centros de poder autonómico y estatal. Su participación en la vida democrática queda así disminuida respecto de los grandes municipios que siempre tendrán medios propios y distintos para ser oídos.

30 El caso de los centros escolares concentrados en unos municipios (con independencia ahora de quién es la Administración competente) a los que se desplazan los pocos niños de otros en los que su escaso número no justifica abrir un centro, pero sí el establecimiento de un sistema de transporte que lleve a los alumnos y los devuelva a sus casas cada día.

31 Artículo 31.2 b) de la LRBRL. 
Nada bueno puede seguirse de todo ello, ni desde luego se conjura la sensación de haber ciudadanos locales de primera y de segunda. En todo caso la sensación de que la democracia local no se perfecciona si queda acantonada en ese ámbito, sin poder trascender al ámbito político autonómico y estatal.

Sólo hay una forma de acceder a ese perfeccionamiento y trascendencia de la democracia local que consiste en que todos sus integrantes -todos los habitantes de la Provincia con independencia de donde viven, aunque sin ignorar este dato- tengan una representación adecuada en la interlocución con los niveles autonómicos y estatal: hacer de la Diputación el vehículo de comunicación y participación de los ciudadanos locales (de todos y cada uno de los diferentes municipios) en la vida política autonómica y estatal mediante los poderes de coordinación e interlocución con niveles superiores que se atribuyen a la Diputación. Ello no quita que los municipios más grandes tengan sus propias vías de participación e interlocución, pero los habitantes de la provincia en su conjunto tienen un vehículo común e igualitario de participación.

Vehículo que culmina y completa el papel y función de la democracia local proyectándola hacia los niveles superiores de gobierno y administración.

Las Diputaciones culminan, perfeccionan y fortifican la democracia local que, aun asentándose básicamente en los municipios, quedaría castrada y falseada sin un órgano de representación provincial de todos los municipios que transcienda y proyecte dicha democracia a ámbitos superiores.

\section{EVENTUAL SUSTITUIBILIDAD DE LAS DIPUTACIONES POR OTRAS ENTIDADES (SUPRAMUNICIPALES, EL MUNICIPIO COMARCA Y LA GARANTÍA DEL MUNICIPIO, O LA CC.AA) EN EL DESEMPEÑO Y REALIZACIÓN DE SUS FUNCIONES PROPIAS}

No parece que pueda negarse que los fines de la Provincia que recoge la LRBRL en el arranque del artículo 31.2 constituyen su fundamento y razón de ser ${ }^{32}$. Tampoco que ese fundamento dota a la Provincia de unas competencias propias y, en todo caso, de unas competencias funcionales que se despliegan y concretan, con geometría variable, cada vez que los municipios por sí solos no pueden cubrir todas las necesidades de la comunidad vecinal cuya cobertura y satisfacción corresponde primariamente a sus Ayuntamientos, si bien en función de su tamaño poblacional; cada vez, también, que la solidaridad y el equilibrio intermunicipales no queden garantizados. Ese papel de la Diputación de alguna forma eleva la población provincial a la categoría de comunidad provincial, por más que la Diputación quede determinada por la agrupación de municipios y no directamente por la suma de los ciudadanos que viven en la provincia con indiferencia respecto del dato del municipio en el que habitan.

Sea como fuere son los ciudadanos de la provincia, pero sin perder de vista su condición de residentes en los distintos municipios, los que determinan a través de sus representantes cómo se plasma la solidaridad y el equilibrio municipal. Y no puede ser de otra forma pues, si no, el núcleo de población más poblado, por el simple dato de tener más habitantes, privaría de todo peso a todos los demás en la determinación de esas políticas de solidaridad y equilibrio. Lo que tiene que ver, como luego se verá, con el problema de la elección directa o de segundo grado en la determinación de los representantes de los municipios en la provincia.

Pero la cuestión ahora consiste en plantearse si es posible que ese papel asignado a la Provincia lo desarrollen otro tipo de Entidades que pudieran sustituirla con ventaja. Se trata de saber si las Comarcas, las veguerías, o incluso agrupaciones de municipios, consorcios o simplemente mancomunidades pueden hacer esa misma función con ventaja sobre la Provincia y por tanto hacerla en algún sentido inútil. Hay quienes incluso reclaman la sustitución de las Diputaciones por las Comunidades autónomas.

De todo ello se trata en el presente apartado empezando por la propuesta que, a nuestro juicio, más se aleja del espíritu constitucional en cuanto a las razones por las que existe la Diputación como es la que consiste en reclamar que ese papel lo realicen las CC.AA (5.1) para a continuación tratar la cuestión de las comarcas como sustitutas de las Diputaciones (5.2) o bien otras organizaciones especializadas como es el caso de agrupaciones de municipios, mancomunidades, consorcios, veguerías, etc. (5.3) con alusión a la singularidad del problema en Cataluña y en Canarias (5.4) y acabar con una reflexión sobre las propias previsiones constitucionales (art. 141.3) y ejemplos comparados acerca de la constitución de agrupaciones de municipios diferentes de la provincia $(5 \cdot 5)$.

32 Vid. GARCÍA MORILLO, J., La configuración constitucional de la autonomía local, Diputació de Barcelona/Marcial Pons, Madrid, 1998; GARCÍA ROCA, J., "El concepto actual de autonomía local según el bloque de la constitucionalidad", en Revista de Estudios de la Administración Local y Autonómica, núm. 282, enero-abril 2000. 


\subsection{Las Comunidades Autónomas como sustitutas de las Diputaciones}

Con frecuencia se invoca el caso de la Comunidades uniprovinciales que han sustituido a las Diputaciones como un ejemplo de que tal cosa no sólo es posible sino aconsejable. Sin embargo, ese ejemplo tal vez sea el más desafortunado que se pueda citar.

Para empezar el caso de las Comunidades Uniprovinciales es bien singular y su propia singularidad no permite su extensión. Su singularidad radica en la resistencia a crear en un espacio tan pequeño otro nivel de Administración, lo que puede explicar la previsión del artículo 9 de la Ley del Proceso Autonómico de integrar en ellas la Diputación provincial que en cada una de ellas habría de existir. De integrarla y de atribuir a la Comunidad la condición de Corporación de carácter representativo que exige el artículo 141.2 de la Constitución en sustitución de la Diputación.

Sin embargo, la operación no puede decirse que, de hecho, haya sido un éxito. Tampoco de Derecho la incorporación se ha hecho de la mejor manera posible, pues se detectan algunas insuficiencias que las uniprovinciales no han corregido en su legislación.

Los defectos son más evidentes cuando se propugna que las funciones de la Diputación las puedan llegar a asumir incluso las Comunidades autónomas pluriprovinciales. La singularidad de las uniprovinciales no parece que sea detectada, probablemente porque se parte de una minusvaloración del papel de la provincia como Entidad local.

El problema radica en que Municipios y Provincias son parte de la Comunidad local integral -conjuntamente son la Comunidad local integral- en tanto que la Comunidad Autónoma es un fenómeno de descentralización política que se mueve a otro nivel. Una cosa es el ciudadano local que pretende resolver los problemas derivados de dicha condición y otra muy distinta ese mismo ciudadano como parte de la Comunidad Autónoma y del Estado. Son dos planos distintos y cuando se mezclan se nos escapa la dimensión característica de cada uno de ellos.

El ámbito de los problemas del ciudadano local abarca a casi todo, pero desde la perspectiva de su concreto y localizado ámbito municipal o provincial. El ciudadano autonómico o estatal (que es el mismo local, desde luego, pero en una dimensión no vinculada a lo local) no está interesado en su ámbito concreto y localizado sino en las cosas que son competencia de la Autonomía o del Estado.

La distinción tiene su importancia, pues absorbida la Diputación (segundo nivel de la democracia local) por la Comunidad el carácter representativo de toda la población de la provincia que ostenta la CA, anula la condición de agrupación de municipios con la que la Constitución caracteriza a la provincia. La anula sin sustituirla por órganos internos de las Comunidades Autónomas en los que estén presentes los municipios como tales participando todos ellos en la formación de la voluntad autonómica en las materias que debiendo corresponder a la Diputación, han sido asumidas por la CA, pero con la obligación para ésta de que a la hora de resolver no debería hacerlo sin tener en cuenta, al asumir el papel de la Diputación, el rasgo de la presencia articulada de todos los municipios para ser oídos antes de la toma de decisión.

Al no haberlo hecho así y sustituir sin más a todos los Ayuntamientos integrados en la Diputación, acaban todos perjudicados y singularmente los más pequeños sin capacidad ni de negociación, participación o interlocución. En el fondo también todos los demás, pues la Comunidad Autónoma prescinde de esa dimensión de democracia local atribuida a representantes locales (no autonómicos) que está ínsita en las Diputaciones.

El carácter representativo de la Comunidad autónoma difumina el rasgo más característico de la Provincia (la idea de agrupación de municipios, su forma de representación y articulación de los municipios y las funciones de solidaridad y reequilibrio atribuidas a órganos de inequívoca raíz local).

Tal cosa podría tener remedio si en su funcionamiento en materias locales dichas Comunidades uniprovinciales hubieran creado internamente comisiones o Consejos con funciones consultivas de carácter preceptivo.

La experiencia en las uniprovinciales no puede ser peor en cuanto a la pérdida del horizonte de la democracia local y, en consecuencia, en la arbitrariedad en el tratamiento de los municipios que integran la provincia y en el desamparo de los más pequeños. Sea como fuere la democracia local ha acabado siendo para las Comunidades Autónomas uniprovinciales un asunto burocrático más y, en todo caso, un asunto de menor interés en comparación con la dimensión política a la que dedican las uniprovinciales sus mayores esfuerzos. Ello, aunque a veces padezcan el espejismo de que hacen cosas en beneficio de los Ayuntamientos; tal vez lo hagan, pero sin los Ayuntamientos la mayor parte de las veces o con acuerdos bilaterales cuya justicia y transparencia no son un modelo.

En la perspectiva de las Comunidades autónomas pluriprovinciales la eventual sustitución que algunos proponen de las Diputaciones por las Comunidades Autónomas supone un grave error y una mutilación de la idea de una democracia local integral que se ha de estructurar, necesariamente, en los dos niveles de democracia 
local (Ayuntamientos y Diputaciones). Tal sustitución en el caso de las pluriprovinciales agravaría el abandono de los municipios de menor población sin capacidad política para negociar y dialogar directamente con la CC.AA. Supondría privar a los municipios de un espacio estrictamente local, desde el cual, coordinarse y articularse los municipios entre sí, antes de negociar o debatir sus intereses con las CC.AA Supondría también desvertebrar toda idea de solidaridad y reequilibrio inter-municipal al desterrar de esa función a los propios municipios afectados.

\subsection{Las comarcas como sustitutas de las Diputaciones}

Las comarcas se han presentado como una alternativa a las Diputaciones cuando en realidad no es esa su finalidad y objetivo. Ello no obstante no puede dejar de reconocerse que una fuerte y exitosa estructura comarcal de toda una Comunidad autónoma supondría, en principio, un serio competidor para la Diputación provincial. Al menos en su función de cooperación y auxilio a los municipios más pequeños.

Ocurre sin embargo que la experiencia de casi cuarenta años no demuestra que las comarcas hayan satisfecho las esperanzas que algunos habrían depositado en ellas. En realidad, sólo Aragón ha seguido una política integral de comercialización de su territorio, pero la experiencia no puede decirse que haya sido exitosa. Como las más limitadas de Cataluña y Asturias confirman.

Pero aparte de ese dato de hecho hay un dato de Derecho que tiene que ver con las funciones de solidaridad y equilibrio inter-municipal que no pueden ser satisfechas por las Comarcas, por el simple dato de que tales funciones sólo podrán darse entre los municipios de cada comarca si acaso, pero nunca entre todos los municipios de la Provincia. En esas condiciones la función de la provincia no puede quedar sustituida por las Comarcas.

Finalmente, no puede olvidarse que cuanto mayor sea el número de Entes que pretendan sustituir a la Diputación en sus funciones de apoyo cooperación a los municipios menores serán las economías de escala y alcance que se consigan. En definitiva, mayores serán los costes. Sería interesante a esos efectos analizar cuáles son los costes de servicios prestados por las comarcas en Aragón comparando entre unas y otras, así como las desigualdades que hayan podido generarse.

De lo que no cabe duda es de que una Diputación para toda una provincia (Zaragoza, por ejemplo) debería obtener unos costes de prestación de los servicios mucho más económicos (por economías de escala y alcance) que los prestados por cada una de las 17 comarcas existentes en esa misma Provincia.

Todo ello unido a que no siempre la Comarca pretende abarcar todo tipo de servicios y, sobre todo, que sus costes son superiores y que las funciones de solidaridad no se suelen producir en el seno de la Comarca y, si se produjeran, no se extienden a las demás comarcas. Todo ello no quita que la comarca tiene un papel que puede ser bien importante, pero sobre todo cuando no pretende sustituir a la provincia en todo En definitiva, la Comarca como alternativa a la Diputación -no desde luego para otras funciones- no produce un efecto beneficioso para la democracia local. Eso sí, la Comunidad autónoma se entenderá más fácilmente con 17 comarcas divididas (con menor poder por su propia división) que con una Provincia única que ha resuelto internamente sus conflictos de interés entre Ayuntamientos antes de dialogar con la CA.

\subsection{Organizaciones especializadas como es el caso de agrupaciones de municipios, mancomunidades, consorcios, veguerías, etc.}

El mismo juicio debe hacerse en relación con otras figuras funcionales que casi por definición tienen su ámbito más limitado. En todo caso en modo alguno pueden sustituir con ventaja a las Diputaciones provinciales en sus cometidos más significativos de solidaridad y equilibrio inter-municipales por su propio ámbito inferior a la provincia33.

\subsection{Singularidad del problema en Cataluña y en Canarias}

Como se ha visto más arriba Cataluña presenta una vieja tradición antiprovincialista que es posible que tenga algunas raíces en la historia y en existencia en otros tiempos de las veguerías. Queda siempre la sospecha de que, además de esa tradición, hay un hecho relevante que debió concretarse en el temor, en el momento

33 Vid. BARRERO RODRÍGUEZ, Concepción, “Las mancomunidades en la Ley 27/2013, de racionalización y sostenibilidad de la Administración local. El mantenimiento final de la situación anterior”, en Memorial para la Reforma del Estado, op. cit., pág. 2091 y ss.; sobre el Consorcio NIETO GARRIDO, Eva, "El Consorcio administrativo", en Memorial para la Reforma del Estado. Estudios en Homenaje al Profesor Santiago Muñoz Machado, CEPC, pág. 2115 y ss. 
naciente de la autonomía, de que en la capital misma de Cataluña hubiera una Diputación tan potente como la de Barcelona durante mucho tiempo dirigida por un grupo político distinto del que estaba al frente de la Comunidad Autónoma.

No tiene sentido aquí entrar en el debate de la funcionalidad mayor o menor de las veguerías en relación con las Diputaciones o sobre su carácter local o periférico. La cuestión pasa por ver si la división territorial provincial prevista en la Constitución puede ser sustituida por otra distinta que coincida con la de las veguerías. Incluso pasa por si las veguerías pueden ser la Institución representativa que prevé el artículo 141.2 de la Constitución, para lo que no parece que hubiera mayor dificultad.

El problema radica pues en el ámbito territorial de las provincias y por el número de éstas, puesto que el artículo 141.1 de la CE reserva a la Ley orgánica la alteración de los límites provinciales.

En realidad, nada se opondría a tal modificación, pero la misma tiene muchas más consecuencias desde el punto de vista electoral ${ }^{34}$. Uno de los problemas derivados radicaría en determinar cuántos senadores va a representar a Cataluña si se pasa de 4 provincias a 7; pero también cuántos diputados dada la garantía constitucional de un mínimo por provincia. Pero hay muchos más. Como es sabido en la historia electoral de muchos países la alteración de los distritos electorales nunca son inocentes. A veces han servido para aplicar las técnicas de Gerrymandering por las que una adecuada división y reordenación de distritos electorales provoca una alteración de quien resulta ganador o perdedor como resultado de la reordenación.

La mera apelación a una algo imprecisa, y en todo caso no definitiva, historia que legitimaría un cambio del ámbito electoral no puede evitar la preocupación sobre los efectos electorales que esas alteraciones de los distritos suelen tener.

En todo caso el primer efecto será sin duda reducir la presencia y la importancia de la Diputación de Barcelona, probablemente vista por la Comunidad autónoma como una competidora ${ }^{35}$.

Con independencia de todo ello, si las veguerías sustituyesen algún día a las provincias lo que el Tribunal Constitucional no objeta ${ }^{36}$, las mismas tendrían que asumir todos los papeles y funciones que las mismas deben asumir. El problema es que cuanto más pequeño sea el ámbito de la provincia/veguería (si de cuatro provincias se pasase a 7) menos capacidad de solidaridad y re-equilibrio municipal podrá hacerse. Por otra parte, cuanto mayor sea al número de Entes provinciales menores serán las economías de escala y alcance que se puedan obtener por la prestación de servicios a los Ayuntamientos desde la Veguería/Provincia. El problema no es, sin embargo, el nombre de veguería, sino la alteración de límites provinciales ${ }^{37}$.

Por lo que respecta a Canarias su situación es bien singular puesto que siendo dos las provincias en que se divide el territorio de la Comunidad no existe Diputación Provincial alguna, sino una especie de zombis de Mancomunidades inter-insulares para "salvar las apariencias" constitucionales. En el fondo se trata de algo bastante normal habida cuenta de que cada isla tiene entidad provincial por lo que no tiene del todo sentido que exista una Diputación provincial.

De hecho, hubo una Diputación provincial hasta 1925 pues, reconstituidos en 1912 los Cabildos insulares con funciones de Diputación provincial, los días de aquella estaban contados y acabó despareciendo siendo sustituida nominalmente por el Estatuto Provincial de 20 de marzo de 1925, título VI por una mancomunidad interinsular de Canarias. Mancomunidad que, a su vez, desapareció al dividirse la Provincia en dos (Real Decreto-ley de 21 de septiembre de 1927) creándose por el Real Decreto-ley de 8 de mayo de 1928 de nuevo dos mancomunidades interinsulares más nominales que otra cosa pues las funciones propias de toda Diputación provincial fueron asumidas por los Cabildos de cada Isla ${ }^{38}$.

La singularidad insular explica esa situación. Sin embargo, no deja de ser anómalo que las competencias, medios y recursos de ambas Mancomunidades fueran asumidas por la Comunidad autónoma en la transitoria del

34 Vid. sobre el tema electoral VV.AA, el capítulo tercero "La provincia como poder público territorial: relaciones entre provincia y municipio. Sistema electoral, forma de gobierno, organización y empleo público de las Diputaciones provinciales”, en el Libro Verde: los gobiernos locales intermedios en España, de la Fundación Democracia y Gobierno Local, 2011, págs. 51 y ss.

35 Esa misma forma de ver las cosas se da en todas las Comunidades Autónomas, aunque faltas de otras tradiciones supramunicipales no han tratado de generalizar otras organizaciones supra-municipales que pudiera reducir la importancia y peso de las Diputaciones. Recuérdese, sin embargo, el peculiar caso de Aragón.

36 Vid. BAYONA ROCAMORA, Antoni, “Régimen Local”, Revista catalana de dret públic (Especial Sentencia sobre el Estatuto), pág. 217 y SS.

37 Vid. BAENA DEL ALCÁZAR, Mariano, "Nota sobre la rigidez constitucional de los límites provinciales. El caso de los enclaves territoriales" en Memorial para la Reforma del Estado", Estudios en Homenaje al Profesor Santiago Muñoz Machado, CEPC, pág. 2019 y ss.

38 Vid. GUIMERÁ PERAZA, Marcos, “La región y Canarias”, Revista de estudios políticos, núm. 179, 1971, págs. 105 a 107. 
Estatuto de Canarias, por lo que dado que Canarias es una Comunidad pluriprovincial las Diputaciones de cada provincia no podían quedar integradas en la Comunidad.

Para salvar las apariencias el artículo 41.2 de la LRBRL declaró la subsistencia de las mancomunidades provinciales interinsulares con imprecisas funciones de pura representación. Se trata de una anomalía, no tanto el hecho de que no haya una Diputación en cada provincia, dada la singularidad insular y la potencia lógica de los Cabildos, sino que subsistan dos provincias cuando ya no tiene sentido alguno las tensiones que llevaron a la división provincial. Y sobre todo cuando el conjunto del archipiélago tiene ya una representación política que es la CA.

Lo mejor sería la unificación en una sola provincia, salvo que eso reavivara viejas e históricas rencillas en Canarias que hoy no deberían tener sentido. Alternativamente prever legalmente la asunción por la Comunidad Autónoma de todas las competencias provinciales que no correspondan a cada provincia, por más que no queda competencia alguna.

En todo caso en los archipiélagos Canario y Balear, la singularidad de la solución deriva de que frente a la isla como hecho central carece de todo sentido una Diputación que esté por encima de la Isla. En realidad, en las Comunidades Autónomas insulares y especialmente en Baleares más que asumir allí la Comunidad Autónoma el papel de la Diputación son las Islas, los Consells, quienes lo han asumido y, además, han añadido a dicha función otras que son propiamente autonómicas. En esas condiciones la problemática de las Islas es tan distinta por el propio hecho geográfico de la insularidad, que poco puede decirse que sirva para el resto.

\subsection{Otras eventuales alternativas a las Diputaciones provinciales: los distritos urbanos, ciudades no adscritas (distritos urbanos o ciudades sin distrito) y ciudades Estados}

Se trata de alternativas que existen en otros países como Alemania o que ha barajado la doctrina de algunos de nuestro entorno como Francia o Italia. Pero no parece que la solución sea fácilmente trasplantable.

El carácter de cooperación y apoyo a los municipios de menor tamaño (sin que se trate tampoco de muy pequeños o diminutos municipios) puede llevar a pensar que, si ese es el papel de las Diputaciones, entonces los municipios más grandes (más de 100.000 habitantes) deberían quedar fuera de la órbita de la Diputación, puesto que con ese tamaño no precisan de ayuda. Tal cosa, sin embargo, no es posible con nuestra Constitución, pero puede haber quienes piensen que la Diputación debería quedar como un instrumento de ayuda a los municipios más pequeños y, en consecuencia, dejar fuera de los mismos, a los que no se ajusten a esa idea de municipios que necesitan en alguna medida la ayuda de ese segundo escalón local que es la Diputación.

A tal efecto se propone como ejemplo el de la ciudad no adscrita (distritos urbanos o ciudades sin distrito) de más de 100.000 en Alemania que quedan en cierto modo fuera del sistema piramidal que culmina en las regiones que existen por debajo de los distintos Estados en Alemania39. Habría también ciudades Estado, aunque estás tienen menor interés para nosotros a los efectos del presente trabajo, pues se sitúan en otro nivel político bien diferente, aunque ponen de manifiesto una concepción distinta del mundo local.

Las diferencias que existen en Alemania entre Entes locales -que en Italia y Francia han jugado algún papel al menos en el plano doctrinal- ponen de relieve una voluntad de tratamiento diferenciado, lo cual puede ser bueno, pero que afecta a la capacidad para que el nivel supramunicipal pueda cumplir adecuadamente su función de solidaridad y reequilibrio al dejar extramuros del sistema de solidaridad que supone la provincia a los Entes locales con más capacidad económica.

Una opción en favor de sacar de la provincia, previa reforma constitucional naturalmente, determinadas ciudades de gran tamaño o, incluso, Áreas metropolitanas, significaría dejar que las zonas más pobladas quedaran al margen del sistema general y, en cambio, las menos pobladas quedarían dentro del ámbito de la Diputación desconectado de las primeras.

El dato de la población, generalmente ligado a la riqueza, acabaría determinando distintos niveles organizativos, dejando fuera a las más capaces económicamente -a las que se les quita el "lastre" de seguir relacionadas con las demás-, pero con ello -aparte de descoyuntar las comunidades que viven sobre un distrito o región- se limita drásticamente la solidaridad y el re-equilibrio territorial al sacar las más pobladas de los distritos en que se integran las menos pobladas.

39 Vid. para Alemania GARCÍA RETORTILLO, Ricard, “La autonomía local en Alemania a los dos siglos de su nacimiento”, en Revista de Estudios de la Administración Local y Autonómica (REALA), núm. 312, págs. 11 y ss. 
Lo mismo ocurriría con las Áreas metropolitanas y con las ciudades capitales. El modelo podría servir para prescindir de las Diputaciones o quitarles poder, pero determinaría un mapa municipal de varias velocidades, divisiones o niveles. En todo caso una concepción de la democracia municipal que no es que rompa con nuestra tradición, sino que altera sustancialmente los valores en que se inspira.

Todas esas alternativas se basan en la idea de sacar de un territorio distintos elementos o piezas del poder local que pierden sustancialmente contactos con los demás elementos y piezas de ese poder local que quedan bajo régimen común.

En nombre de la eficacia puede tener su lógica esa propuesta, pero en nombre de la democracia y la solidaridad rompe la que preside nuestra idea del poder municipal. Por otra parte, al desarticular el espacio provincial - o el ámbito de actuación funcional de la Diputación- en tanto componentes como diferencias puede haber, sin punto de contacto entre ellos, debilita la idea misma de una democracia municipal integral.

\section{REFORMAS INDISPENSABLES EN LAS DIPUTACIONES QUE HAGAN FRENTE A LOS DERROCHES CORRUPCIÓN CACIQUISMO, ETC.}

Unos importantes papeles en la puesta en cuestión de las Diputaciones han jugado las críticas a los excesos de gastos, caciquismo, nepotismo y corrupción que se han divulgado por la prensa durante los últimos años. Críticas que en muchos casos se han visto acompañadas de persecución judicial y condenas. El conocimiento de esos defectos en el funcionamiento de las Diputaciones ha inclinado a muchos a considerar innecesarias las Diputaciones.

En la misma línea se muestran determinados análisis, algunos muy meritorios ${ }^{40}$, sobre la eficacia de las Diputaciones en los últimos años con estudio de las inversiones de las Diputaciones y de los gastos corrientes en que incurren o del nivel de ejecución de sus presupuestos o de sus endeudamientos y déficit etc., etc. Varios de ellos concluyen con propuestas de supresión.

El problema de todos esos estudios radica en que si ese criterio de que los fallos y excesos en que han podido incurrir algunas Diputaciones se aplicase con la misma lógica a las demás Instituciones en que se han dado tales excesos entonces habría que concluir en la supresión de más de un nivel de Administración empezando por el estatal, pues si hay corrupción en el Gobierno del Estado o en los de las Comunidades autónomas, también habría que suprimirlos.

Pero, como es lógico, eso no puede ser un argumento. Sólo puede ser una razón que lleve a la supresión de una Institución siempre que ésta se considere innecesaria y siempre que, aun siendo necesaria o al menos conveniente, no sea posible limpiarla o despojarla de todos esos excesos. No se trata de suprimir sino de reformar las Instituciones para que no haya corrupción, nepotismo, caciquismo etc., en las Instituciones que sean necesarias y convenientes.

Lo importante a los efectos que aquí interesan no es que haya corrupción, caciquismo o nepotismo, sino corregir las cosas para que esos fallos no se den más. Lo importante es, para empezar, determinar si el papel de las Diputaciones lo consideramos necesario o conveniente y no fácilmente sustituible por otras instancias.

En definitiva, si la Provincia tiene una función propia, como aquí se sostiene, no se trata de suprimirla sino de mejorarla. Tanto para suprimir las corrupciones y corruptelas como para lograr que cumpla mejor su función. Las soluciones para lo primero pueden ser varias como la adopción de mecanismos de supervisión y garantía, aparte, por supuesto de los penales. Más valen mecanismos preventivos que esperar y confiar sólo en los penales. Estos, sin duda, habrán de emplearse, pero más importante es la prevención con mecanismos de control interno, con un régimen de protección a quienes denuncien prácticas corruptas o con la inclusión de los corruptores y de las sociedades para quienes trabajen, aunque no sean sus administradores o representantes, en las prohibiciones para contratar con cualquier Administración que se establecen en el artículo 60 del texto refundido de la Ley de Contratos del Sector público, etc., etc., etc.

La prevención, aparte de mecanismos de intervención y transparencia, consiste también en checks and balances como nos tiene enseñados la experiencia americana. En definitiva, un sistema de equilibrios y reparto del poder de forma que nadie concentre demasiado poder como para no sentirse vigilado por otras personas u órganos.

En todo caso lo que aquí quiere señalarse es que los casos de corrupción, ineficacia, nepotismo, etc., no son, en sí mismos, argumentos para suprimir las Diputaciones, como no lo son para suprimir el Estado o las Comunidades autónomas. 2016.

40 Vid. VV.AA, "Coste y utilidad de las diputaciones provinciales: claves para un debate necesario", Informe de la Fundación ¿Hay Derecho?, 
Lo que es preciso es valorar si el papel que les asigna la Constitución a determinados Organismos o Instituciones les hace acreedores a su existencia y en tal caso valorar qué mejoras habría que introducir, tanto para evitar corrupción y nepotismo, como para mejorar su eficacia, garantizando su transparencia y el seguimiento de su funcionamiento y gestión.

Con independencia de esas cuestiones hay una segunda objeción importante que se hace a las Diputaciones y que tiene que ver con la forma como se nombra a los miembros de las mismas; a los diputados provinciales. Se trata, como es sabido, de sistemas de elección indirecta en que no participan directamente los electores, sino que lo hacen los concejales elegidos para los Ayuntamientos de los partidos judiciales en que se integran los Ayuntamientos a los efectos de la designación de Diputados con una aplicación previa de la regla d'Hondt para saber los puestos que corresponden a partidos y agrupaciones. El Tribunal Constitucional ha avalado la constitucionalidad del sistema (Sentencia 109/1998), lo que no quita que desde el punto de vista de la conveniencia o de si hay mejores soluciones haya sido objeto de críticas ${ }^{41}$. En todo caso se ha acusado de falta de democracia por la falta de elección directa, lo que no es muy exacto puesto que hay una participación de los electores siquiera sea indirecta; acusación que se hace no tanto para mejorar el sistema sino, muchas veces, para justificar la supresión de las Diputaciones.

Ese sistema indirecto de elección sería para muchos la causa de las corrupciones y corruptelas que en algunas Diputaciones se han podido producir; también la causa de sus ineficiencias. Los diputados provinciales no se sentirían responsables ante nadie, ni siquiera ante los concejales de los municipios que han participado en la votación para su designación.

No cabe duda de que el hecho de que la representación no sea directa parece que disminuye la responsabilidad frente a unos inexistentes ciudadanos electores. La observación tiene algún peso y por eso merece detenerse un momento en ella.

La primera reflexión que puede hacerse radica en que los sistemas de elección directa en otros ámbitos, como Ayuntamientos y CA, no han garantizado contra tales corrupciones o corruptelas, pese a darse tal elección directa. Las listas cerradas y bloqueadas no permiten conocer a los representantes que elegimos, salvo tal vez al primero de la lista y ello también determina que la mayoría de los elegidos se sientan básicamente responsables, no tanto frente a sus electores, sino frente al órgano del partido que puso su nombre en la lista. La elección indirecta no sería así la determinante de las malas prácticas, corruptelas o corrupciones, puesto que en sistemas basados en elección directa esos mismos defectos se han podido presentar.

Ello no obstante la mayor distancia respecto del elector puede favorecer una cierta sensación de lejanía y aún de impunidad de los representantes a efectos de corruptelas o ineficiencias. La solución a estos últimos problemas viene por otras vías y algunas hemos enunciado más arriba.

En todo caso la elección directa por los electores plantea un problema no menor, sobre los que ya tiene ${ }^{42}$. En efecto, si la elección se hace entre todos los habitantes de la provincia y no por partidos judiciales el resultado quedaría totalmente distorsionado por la preferencia de los votantes de la capital de la misma o de los municipios más poblados, sacrificando la presencia de los menos poblados. Eso explica el sistema de votación por partidos judiciales, realizado por los elegidos en el ámbito municipal que se objeta a veces como un sistema de difícil justificación, cuando en realidad lo que trata es de que haya un cierto equilibrio intermunicipal, de forma que la Diputación no represente sólo a los ciudadanos, sino a los mismos en su condición de residentes en unas determinadas zonas con la idea de que exista un cierto equilibrio territorial. Garantizando, por ejemplo, un mínimo de representatividad a cada zona o partido judicial elegido.

Como es lógico eso plantea la cuestión de cómo y con qué criterios se ha hecho la inclusión de cada municipio en uno u otro partido judicial que ha sido la referencia utilizada en su día por la Ley electoral ${ }^{43}$. A nadie se le escapa que esa inclusión o exclusión en un determinado partido judicial podría tener efectos de Gerrymandering, pero la referencia al partido judicial, concebido a otros efectos, probablemente, sea bastante aséptica. En todo caso es algo que los expertos podrían revisar.

41 SALVADOR CRESPO, Mayte, Algunas pistas para entender las elecciones locales en clave provincial, Instituto de Derecho Local, blog, Mayo 2015.

42 Vid. BELTRÁN DE FELIPE, Miguel, "¿Pueden ser concejales, o miembros del órgano de gobierno local, personas que no hayan sido elegidas por los ciudadanos? Reflexiones sobre la reciente jurisprudencia constitucional y la democracia local”, en Memorial para la Reforma del Estado, op. cit., pág. 2137 y ss.

43 Vid. GARRIDO LÓPEZ, Carlos, “Elección de diputados provinciales y ruptura de la relación representativa”, en Revista Debates Cons-

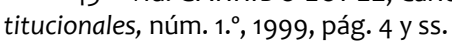


De cualquier manera no parece que esa garantía de presencia de todos los territorios sea algo de lo que se pueda prescindir sin consecuencias para la propia función de las Diputaciones. En cambio, algo en lo que se podría reflexionar es en si la elección podría hacerse de forma directa por los ciudadanos de cada partido judicial, de forma que en las urnas de cada colegio además de votar los concejales de su preferencia en la urna municipal, se votase directamente en otra urna por los Diputados provinciales ${ }^{44}$.

No es el caso de profundizar aquí, dada la naturaleza del presente trabajo, en cómo mejorar el sistema electoral de las Diputaciones, sino sólo señalar los condicionamientos que al sistema de elección directa le imponen dos requisitos. De una parte la necesidad de que en la Diputación haya una garantía de representación territorial que no puede vincularse a que cada municipio tenga al menos un representante, pues entonces sería inmanejable el número de representantes y de ahí el partido judicial; de otra la necesidad de que el representante del Partido judicial-o los representantes si hubiera más de uno- sea el intérprete de los intereses de los Ayuntamientos del Partido y la dificultad que se puede derivar para ello del hecho de que el, o los representantes de cada partido judicial, elegido directamente por los vecinos de tal partido judicial (que es en realidad una unidad virtual de convivencia), actúe descoordinadamente y aún en contra -dada su legitimidad propia obtenida directamente de los vecinos del Partido judicial y no de los Ayuntamientos- de los intereses de los municipios comprendidos en el Partido judicial; o, para ser más precisos, en contra de la forma en que tales intereses son entendidos por los Ayuntamientos que el Diputado por el Partido Judicial correspondiente puede entender que deben ser interpretados y defendidos de otra manera.

En definitiva, la elección directa por los habitantes de toda la provincia desfigura la presencia y equilibrio de los municipios menores en la representación por un lado y, por otro, la elección directa por Partidos judiciales plantea también otros problemas de no fácil solución. En todo caso el principal radica en cómo articular una elección directa de los Diputados con la necesaria coordinación de éstos con los Ayuntamientos o sus concejales para determinar quién y cómo determina cuáles son los intereses a defender y la forma de hacerlo. Problema no menor cuando las partes involucradas -los diputados del Partido judicial y los concejales de los Ayuntamientos de ese mismo Partido judicial- tienen ambos un mandato electoral directo de gestionar los intereses municipales en su dimensión propia y en la configuración de los intereses supramunicipales.

Una última objeción suele hacerse y es la del gasto que supone el mantenimiento de las Diputaciones con cuya supresión se podrían obtener algunas economías de gasto. Habría que empezar por distinguir entre el aparato administrativo de la Diputación por un lado y, por otro, el aparato político con los Diputados elegidos que integran cada Diputación. Como es lógico del aparato administrativo no se puede prescindir, pues el mismo es el que procurar la asistencia y ayuda a los municipios; también el que preparar con los distintos técnicos los planes provinciales o los proyectos de obra que se van a licitar o a ejecutar directamente por la Diputación, etc.

Cuando se habla de ahorro de gasto se está pensando en la parte política de la Diputación, lo cual reduce significativamente la importancia del pretendido ahorro. Se reduce su importancia si se piensa sólo en el Presidente de la Diputación y en los Diputados y en el personal que pueda relacionarse específicamente con los Diputados. Esos gastos pueden ajustarse o reducirse sin necesidad de suprimir las Diputaciones mismas; así ocurre cuando se limitan las cantidades a percibir o el personal que se puede contratar y algo ha querido hacer la Ley 27/2013, de 27 de diciembre, de racionalización y sostenibilidad de la Administración Local en sus artículos 75 bis y siguientes. En todo caso sin perjuicio de avanzar en el ajuste de esos gastos la desaparición de una Institución no puede fundarse en el gasto que produce, aunque deba tenerse en cuenta, desde luego, sino en si es necesaria o conveniente o no. En otro caso sobrarían todos los Parlamentos del mundo porque sería tendría menos gastos un presidente ejecutivo o un dictador que un parlamento.

Por otra parte, los sistemas de sustitución que se propugnan, como Consejos de Alcaldes no parecen muy meditados en los problemas que plantean. Para empezar, en la falta de dedicación al segundo nivel de democracia local que supone que un Alcalde que se debe en primer término a su municipio pueda dedicarse seriamente a los problemas del conjunto de los municipios con los que con frecuencia tendrá conflictos de intereses que no es lógico que se quieran resolver a base de votar en ese Consejo de Alcaldes; parece mejor que sin perder la perspectiva territorial haya algo más de distancia emocional para encontrar soluciones de interés supramunicipal que los Alcaldes muy involucrados en los intereses particulares de su municipio y presionados por sus electores y por los medios de comunicación no están en las mejores condiciones para encontrar soluciones conjuntas.

44 Otra alternativa sería que en la propia papeleta para votar a concejales se estableciera quién de entre ellos se propone para Diputado provincial, aunque el problema aquí radica en que, en la hipótesis de que en un determinado partido judicial sólo hubiera un puesto de Diputado para ese partido, los municipios de dicho partido judicial en cuyas listas no fuera el propuesto para Diputado no podrían votarle. Sólo los electores del municipio del Partido judicial en que vaya el concejal propuesto para Diputado tendrían la oportunidad de votarle. 
Pero por otra parte esos Alcaldes no pueden ir todos y es posible que los pertenecientes a municipios más grandes acaben imponiendo su voluntad y con ello rompiendo la dimensión territorial de garantía de un mínimo de representación para cada partido judicial que es la garantía de que los municipios más poblados sean los únicos que interpreten, siendo jueces y parte, qué debe entenderse por solidaridad y equilibrio inter-municipal.

\section{CONSIDERACIONES FINALES}

Cuanto hasta aquí se ha dicho trata de mostrar que las Diputaciones no solo son una Institución que tiene una historia detrás, sino que tiene un papel y una función que puede considerarse clave para llevar a su plenitud lo que hemos denominado democracia local integral.

Democracia local plena que no se lograría entregando a las Comunidades Autónomas las funciones de las Diputaciones. Tampoco con fórmulas que confíen en comarcas el papel que las Diputaciones tienen, siendo las comarcas la Institución que más podría competir con la Diputación en ese papel de culminar la democracia local.

Sin embargo, al margen del poco desarrollo de las comarcas en España o del relativo fracaso o irrelevancia de las mismas allí donde se han creado, las mismas nunca podrán desempeñar las funciones de solidaridad y reequilibrio que la Constitución quiere que tenga un marco provincial y no comarcal. Ello no obstante la provincia no puede ser tampoco un impedimento para que las comarcas puedan crearse y lleguen a ocupar el papel y función de las Diputaciones, que quedarán relegadas a una estructura de reserva por si tal cosa no ocurriese o por si hubiera funciones que no lleguen a atender las comarcas.

La provincia puede así ofrece márgenes de flexibilidad en los términos delineados por la Constitución; flexibilidad que se concretaría tanto con la posibilidad de ser sustituidas por otras Corporaciones de carácter representativo, como por el dato de que la misma no agota otras posibilidades de agrupación de municipios dentro de la provincia. Las Diputaciones serían en todo caso un modelo por defecto de culminación de la democracia local que quedará en todo caso como una red de seguridad de que la democracia local plena, que precisa de Instituciones supramunicipales, no quede en riesgo de no llegar a culminar por inexistencia de esas otras Instituciones supramunicipales o porque existiendo no satisfagan correctamente su función. Hasta ahora no ha habido ejemplo alguno en nuestro país de que esas otras Instituciones hayan cumplido plena y generalizadamente el papel que se podía esperar de ellas.

Una supresión de la provincia de la Constitución condenaría la democracia local a no culminar en plenitud y, probablemente, a una reducción del número de Ayuntamientos con menor población, incapaces por sí mismos de prestar determinados servicios. A una reducción porque la explicación más plausible a la desaparición de las Diputaciones sería porque habrían desaparecido aquellos municipios de menor tamaño que precisan de la existencia de la Diputación.

Desde una visión puramente económica tal cosa podría parecer un éxito. Desde una visión democrática, iniciada en Cádiz, sería un empobrecimiento de la democracia local, en cuanto renuncia a mantener, entre los vecinos de los municipios afectados por su desaparición ${ }^{45}$, el sentimiento de ser dueños del espacio local en el que viven; sentimiento que es el primer germen de la vida en democracia total.

45 Se trata de 15 millones de ciudadanos que viven en poblaciones de menos de 20.000 habitantes. De ellos 12 millones viven en pueblos y ciudades de más de 1000 habitantes. 